\title{
A Teaching Model for College Learners of Japanese Based on Online Learning
}

\author{
https://doi.org/10.3991/ijet.v15i15.15929 \\ Dongmei Jin $\left.{ }^{(}\right)$, Yiping Li \\ Jilin Institute of Chemical Technology, Jilin, China \\ jdongmesohu.com
}

\begin{abstract}
Online learning has not been fully implemented by college Japanese teachers, due to the lack of supports from intelligent technology and the poor decision-making of college management. This paper attempts to develop a teaching model that effectively integrates online learning to enhance the learning ability of Japanese among college students. To begin with, the authors summarized the status quo, impacts, and problems of online learning among Japanese learners in colleges. Through expert survey and literature review, an index system was established to measure the online learning ability of Japanese among college students. The weight of each index was determined by analytic hierarchy process (AHP). Based on index system, a grey relational analysis (GRA) model was set up to evaluate the online learning ability of Japanese among college students. The research results provide a good reference for the online learning of other language majors.
\end{abstract}

Keywords_-Japanese, online learning, learning ability, teaching model.

\section{$1 \quad$ Introduction}

Following the continuous development of network technology, the teaching model of modern higher education has been gradually changing from the traditional classroom teaching to the online learning, which plays a very active role in current higher education [1-3]. Especially due to the urgent needs of foreign exchanges between countries around the world, the college teaching of foreign language is required to combine the artificial intelligence technology to improve the teaching model, with the aim of training senior professionals who are more in line with the development of the times and foreign language talents with higher comprehensive quality. Through the comprehensive application of network technology, computer technology, information technology, big data technology, multimedia technology, and virtual reality technology, etc., foreign language professional knowledge will be accurately pushed through the online form to college students based on their curriculum planning and learning needs. This can help to realize the rational use of foreign language learning resources, fully mobilize the interest and enthusiasm of foreign language majors in autonomous learning, enhance the self-learning ability, and improve the learning effects and quality [4-6]. College Japanese is an important part of foreign language majors in colleges. 
In recent years, the Japanese teaching model based on online learning has attracted the attention of many researchers. A series of academic studies have been carried out, achieving many research results, which have important guiding significance for improving the learning ability of Japanese. For example, Wu et al. analyzed the impact of college students' Japanese learning attitudes on learning input, and explored the implementation of relevant strategies for Japanese professional education reform in the era of big data [7]. Li discussed about how to cultivate students' interest in college Japanese teaching under the new national standard framework [8]. Osipov et al. introduced and analyzed a new online foreign language learning platform [9]. Buyse and Verlinde took Linguee and the interactive language toolbox as examples to study the impact of free online data-driven dictionary tools on foreign language learning [10]. From the perspective of knowledge transformation, Jiang conducted a comparative analysis of online learning platforms for online courses in Chinese and American universities [11]. Gao and Qin probed into how to digitalize Japanese teaching environment from the view of ecology [12]. Zhou studied the reform of Japanese teaching through the survey analysis for the current Japanese teaching in a college [13].

However, at present, online learning has not been fully implemented by college Japanese teachers, due to the lack of supports from intelligent technology and the poor decision-making of college management. This leads to some problems with the online learning of college Japanese majors and influences their learning ability to certain degree. To this end, this paper attempts to deeply study the teaching model for college learners of Japanese based on online learning. It combined with the existing research results, and applied the gray theory [14-16] and AHP method in this study. This paper consists of 5 parts: the first part summarized and analyzed the status quo and impact of online learning among Japanese learners in colleges; the second part focuses on the problems existing in online learning of Japanese for college students; the third part discussed about the implementation of the strategy for the online learning model; the fourth part analyzed the evaluation of online learning ability of Japanese learners in colleges, and establishes the corresponding index system and GRA model; the fifth part gives the conclusion.

\section{Analysis for Problems Existing in Online Learning of Japanese Learners in Colleges}

\subsection{Weak technical support}

At present, with the rapid development of artificial intelligence technology, the application level of network technology, information technology and computer technology has also been significantly improved. However, the artificial intelligence technology hasn't been applied deeply in higher education, and its main functions are reflected in the aspects of education management and informatization office, but the technical support capacity for college teaching is still slightly inadequate. Especially, online learning of minority languages such as Japanese, requires comprehensive knowledge transfer in terms of listening, speaking, reading, writing, and translating 
etc. It relies only on existing multimedia technology or network applet technology, which can no longer meet the online learning needs of Japanese majors, Thus, it urgently needs support in the existing technical conditions, continuously increase the introduction and in-depth application of advanced intelligent technology, and improve the technical support means and ability for online learning of Japanese in colleges.

\subsection{Poor professionalism and low practicability of the platform}

It can be seen from the application of the existing online learning platforms in colleges, the MOOC teaching platform, flip class teaching platform, NetEase cloud class platform, rain classroom platform, Tencent class, Baidu Chuanke, and Taobao education, etc. all have good universality and framework. They have a great application effect in higher education with common learning features or learning functions, but still need further development in terms of professionalism and applicability, because it is often difficult to meet the personalized online learning needs of minority languages such as college Japanese. Especially for the online learning requiring different dimensions such as hearing, vision, and feeling, its practicality needs to be further improved.

\subsection{Insufficient online learning resources and curriculum planning}

Nowadays, the construction of online learning platforms and systems for Japanese learners in colleges often focuses only on the development of certain functional modules. For instance, some online learning platforms or systems focus on the development of teaching modules for specific courses; some emphasize on the development of interactive modules for homework exercises after class; some others focus on the construction of specific curriculum resource modules. From a functional point of view, these online learning platforms or systems all have a certain functional framework, but the online learning resources supporting these functional frameworks are often inadequate, and these resources are generally displayed to students in the form of classroom video files, text files, and audio files of specific courses. In addition to the insufficient online learning resources and single form, there is no systematic planning of online course resources, which causes students to conduct online learning passively, and seriously affects students' systematic learning of professional knowledge and reduces their enthusiasm and initiative.

\subsection{Poor shareability of online learning resources}

An important purpose of online learning in colleges is to spawn many classic online e-learning course, improve the construction ability of online e-learning courses, and promote the effective integration and sharing of these high-quality teaching resources, thereby realizing the continuous accumulation and growth of online learning resources. However, it can be seen from the current implementation of online learning in colleges that due to the different technical standards and specifications for online elearning platforms, the application interface of resource sharing often has access re- 
strictions. Meanwhile, when different colleges conduct planning of online resources, there are often requirements for their own management mechanism, especially for intellectual property issues related to teaching resources, which results in the difficulty of exchanging online learning resources. When it involves two-way communication and interaction of online learning resources, there are often many constraints, so that online learning resources sharing fails to reach the expected effects.

\subsection{Inadequate management capacity of online learning management ability}

Many colleges generally only focus on the early-stage construction of the online learning platform, but ignoring the necessary management for its later-stage construction, operation, and maintenance. As mentioned earlier, some online learning platforms have constructed the platform function framework in the early stage of the construction. However, due to new demands of teaching or management in the application process, it's necessary to increase the teaching function or management function. Without sufficient adaptability, the platform cannot carry out effect construction and upgrading. In addition, because of the time-effectiveness nature, some teaching resource are outdated or can no longer meet the current teaching requirements with the continuous progress of teaching. But there is no timely update or replacement on the online learning platform, and even some online learning resources cannot be accessed effectively.

\subsection{Low evaluation ability of online learning}

The evaluation of online learning is mainly performed from three aspects: the teacher's online teaching, the student's online learning, and the interaction between teachers and students in the online learning model. First. the evaluation of the teacher's online teaching mainly includes the completion of the teacher's online teaching tasks, the explanation of the online teaching content, the online teaching effect, and the teacher's mastery of the students' online learning progress. Second. the evaluation of students' online learning mainly includes the completion of students' learning tasks, feedback on learning problems, satisfaction with online teaching resources or teaching content, etc. Thirdly, the interaction between teachers and students is mainly reflected in their online and offline interaction, so that students can reflect learning problems in a timely manner, and teachers can feedback information to students in a timely manner, thereby narrowing the emotional distance between the and creating a good online and offline learning environment. In this way, students' enthusiasm for learning shall be simulated. However, judging from the current implementation of online learning in colleges, online learning only attaches importance to the teaching link of teachers, while ignoring the learning of students and the interaction between teachers and students. 


\section{Implementation of the Teaching Model for Japanese Learners in Colleges Based on Online Learning}

\subsection{Strengthening the construction of online learning platform for Japanese learners in colleges}

The basic guarantee condition for online learning of Japanese among college students is the support of a good online learning platform. Under the support of artificial intelligent technology, the current mature network platform construction technology is usually used to develop online learning platforms for college students, which is the mainstream form of online learning. Especially for the specialized learning of foreign languages such as Japanese, the related online learning platform need to be customized in accordance with the specific conditions of professional learning, so that they can more effectively support Japanese language learning of college students. Through the construction and implementation of the Japanese language learning platform for college students, on the one hand, it cannot only enable college Japanese majors to use scattered and fragmented time and learn Japanese professional knowledge, but also enhance the freedom and controllability of Japanese learning time so that they can arrange the learning schedule according to individual learning situation; on the other hand, a Japanese language learning platform for college students with multimodal characteristics is built to stimulate the sensuality and situationality according to the characteristics of college students' language learning, which can fully mobilize college students' interest and willingness to learn Japanese, and in turn creates an excellent Japanese learning environment and attitude for college students. For this, when strengthening the construction of the Japanese language learning platform for college students, it's necessary to consider the comprehensive utilization of various mature artificial intelligence technologies, and form a more comprehensive online learning platform through the fusion of computer technology, network technology, information technology, virtual reality technology, multimedia technology, etc. At the same time, for the online learning platforms having more or stricter requirements, generally the customized design of online learning modules is made based on a typi$\mathrm{cal}$ online learning platform to meet various forms of learning requirements. Currently, the platforms such as MOOC Class and Rain Classroom, etc. are mostly used in higher education, which provide a good reference for the construction of Japanese language learning platforms for college students.

\subsection{Enriching teaching resources for online learning of Japanese learners in colleges}

One main purpose of online learning of Japanese for college students is to obtain more abundant Japanese learning resources. To this end, in the constructing process of a Japanese online learning system for college students, the teaching resources for online learning should be ensured in the aspects of different types, forms, levels, and perspectives, etc. Firstly, in terms of different types, Japanese online learning re- 
sources are enriched for college students through multiple setting and display of college Japanese resources in listening, reading, speaking, and writing, etc., to ensure the college students' online learning of Japanese in a targeted manner. Secondly, in terms of different forms, online learning resources are enriched by setting and displaying multiple forms of materials such as video materials, audio materials, text materials, and model materials of college Japanese, so that college students can combine different forms of online learning materials to impart and consolidate knowledge during their online learning. Thirdly, the setting and display of learning resources according to the level or professional level of college Japanese learners help to enrich the online learning resources of Japanese language for college students. For example, the online learning resources of Japanese language can be classified in terms of graduates and undergraduates. The difficulty and depth of online learning resources for graduate students is correspondingly higher than that of undergraduates, and has a strong professionalism. Moreover, the online learning resources for Japanese language of graduate students can be subdivided into multiple levels for first-year graduates, secondyear graduates, third-year graduates, and doctoral students etc., while Japanese online learning resources for undergraduates can also be subdivided into multiple levels for lower grades and higher grades college students. Thus, Japanese majors can intuitively select the corresponding online learning resources according to their own learning grade or stage. Finally, the online learning resources of Japanese language for college students are also enriched from the professional, practical, theoretical, and other perspectives of college Japanese. For example, set up professional courses based on Japanese grammar and professional knowledge points; open practical courses or theoretical courses better trigger students' interest in learning, and cultivate students' language practice ability or theoretical learning ability. Enriching the teaching resources of online learning for Japanese learners in colleges cannot only meet the online learning needs of Japanese majors, and provide more professional knowledge, so that they have more learning options; but also plan their own learning plans according to their individual learning interests, leading to positive changes in the individual's selflearning atmosphere and learning effect, and more effectively enhancing the learning autonomy of individuals.

\subsection{Enhancing the ability of online learning to push professional knowledge}

Traditional Japanese language teaching in colleges mostly adopts the classroom teaching model to impart professional knowledge, and sometimes combines with assisted teaching such as multimedia classrooms or learning applets. But this teaching model is mainly based on the face-to-face communication between teachers and students in the classrooms, and the number of Japanese teachers' professional knowledge reserves directly determines the ability to teach professional knowledge in classroom teaching, that is, the upper limit of Japanese professional knowledge transfer is certain. The teaching model based on online learning is also used to impart Japanese professional knowledge. With the continuous increasing of technical support capabilities in database technology, information technology, network technology and computer technology, Japanese online resources have begun to increase in the orders of mag- 
nitude, the reserve capacity of Japanese professional knowledge has been getting stronger, and Japanese professional knowledge has also been richer. Thus, it has become an important part of Japanese professional knowledge teaching on how to obtain effective and reasonable professional knowledge in this massive Japanese knowledge base. Especially following the rapid development of big data technology, the professional knowledge that meets the learning needs of students needs to be pushed from many knowledge sources. As above, the authors believe that enhancing the ability of online learning to push professional knowledge is a very important factor to improve the learning ability of current Japanese learners in colleges. For this, related work need to be done in three aspects: one is to do a good job of pushing the pre-class knowledge of online learning to each student in advance, including the preparation content of pre-class Japanese language learning and key conceptual and framework knowledge so that they can well prepare for the class; the second is to well push the classroom knowledge for Japanese leaners based on online learning, that is, according to the course progress, the key and difficult points of the classroom are displayed to the students in time, and knowledge extension can be carryout out in time, to ensure classroom learning effect; the third is to well push the after-class knowledge push for Japanese majors, answer the students' questions in a timely manner, push the afterclass exercises and extracurricular learning materials to the students in time, and achieve the accurate control of their learning progress; besides, it forms learning data that can be used to quantify the learning effects, find the weak links of learning through model analysis of the learning data, and then specifically push the professional knowledge according to the weak links of Japanese professional learning.

\subsection{Improving the interactive communication among Japanese learners in colleges}

As the online Japanese courses and online learning resources continuously increase, some Japanese learners in colleges will inevitably face various forms of learning problems during the online learning. If these learning problems cannot be solved effectively, it will affect the follow-up Japanese online learning program for these students, or even their online learning interest. In addition, due to the difference in understanding and cognitive ability of different students, their understanding of Japanese professional knowledge also varies. Some students may quickly absorb and learn professional Japanese knowledge, while some others may need multiple explanations or practical exercises to deepen their understanding. This requires Japanese majors to fully and timely interact and communicate with Japanese teachers in the process of online learning. In addition, Japanese learners of different grades have different levels of professional knowledge. The learning experience of the senior students often provides a good reference for the junior Japanese learners, helping to improve their online learning efficiency and learning quality. Thus, from the perspectives of Japanese teachers' classroom teaching and Japanese leaners' after-class learning, a good interactive platform for the Japanese learners in colleges should be established to improve their communication in online learning of Japanese and further promote the online learning effect and learning quality. 


\subsection{Enhancing the evaluation of the online learning effect for Japanese learners in colleges}

For online learning of Japanese learners in colleges, in addition to timely following the progress of online teaching and online learning, it's also necessary to learn about the online learning effect. The effective measurement of the online learning effect is conductive to determining the effectiveness and feasibility of the current online learning model for Japanese learners. If the current online learning effect fails to meet the teaching goals, weak links of the current online learning need to be found, and targeted measures and strategies should be taken to improve the online learning effects. If the current online learning effect meets the teaching goals, it is necessary to analyze the follow-up sustainability of the current online learning model, and make a future development plan. For this, the authors believe that the evaluation of the online learning effect should be prepared in two aspects: first, construct a set of highly targeted assessment system for online learning effect of Japanese learners in colleges based on the goal requirements of the online learning effect assessment; second, establish a quantitative analysis model under the evaluation system of online learning effect, to effectively evaluate the online learning effect for Japanese learners.

\section{Evaluation Analysis for Online Learning Ability of Japanese Learners in Colleges}

\subsection{Selection of evaluation index}

From the above, the Japanese learning ability of college students based on online learning is affected by both the learning factors of students, the management factors, and the teaching factors of teachers. Therefore, the evaluation index for online learning ability of Japanese among college students needs to be comprehensively selected from multiple aspects.

Table 1. Sub-evaluation system (1)

\begin{tabular}{|c|l|c|}
\hline Evaluation system & \multicolumn{1}{|c|}{ Evaluation index } & Symbols \\
\hline \multirow{4}{*}{$\begin{array}{l}\text { Evaluation index system } \\
\text { of online learning effects } \\
\text { for college Japanese } \\
\text { leaners based on a learn } \\
\text { ing perspective } S_{1}\end{array}$} & The rationality of online learning time allocation & $S_{11}$ \\
\cline { 2 - 3 } & Ability to control online learning progress & $S_{12}$ \\
\cline { 2 - 3 } & Autonomous ability in online learning & $S_{13}$ \\
\cline { 2 - 3 } & $\begin{array}{l}\text { Innovative thinking ability in online learning } \\
\text { Interactive communication ability for online learning }\end{array}$ \\
\cline { 2 - 3 } & Ability to absorb and digest knowledge in online learning & $S_{14}$ \\
\cline { 2 - 3 } & Learning effect or results of online learning & $S_{16}$ \\
\hline
\end{tabular}

First, from the aspect of the Japanese learners' online learning effect in colleges. the selection of evaluation index mainly focuses on their online learning process and the learning effects under the online learning mode. Based on expert survey and the 
existing literature review, the authors proposed an online learning effect evaluation system for college Japanese learners on a learning perspective, as shown in Table 1.

Secondly, from the aspects of the teaching and management. the selection of evaluation index mainly focuses on the implementation of online teachers and management, as well as the learning effects under the online learning mode. Based on expert survey and the existing literature review, the authors proposed an online learning effect evaluation system for college Japanese learners on the perspectives of teaching and management, as shown in Table 2.

Table 2. Sub-evaluation index system (2)

\begin{tabular}{|c|c|c|}
\hline Evaluation system & Evaluation index & Symbols \\
\hline \multirow{5}{*}{$\begin{array}{l}\text { Evaluation index system of } \\
\text { online learning effect among } \\
\text { college Japanese learners on } \\
\text { the teaching and management } \\
\text { perspectives } S_{2}\end{array}$} & Rationality of the online teaching plan & $s_{21}$ \\
\hline & Systematicness of online learning content & $s_{22}$ \\
\hline & Abundance of online learning resources & $s_{23}$ \\
\hline & Timeliness of information feedback in online teaching & $s_{24}$ \\
\hline & Advancement of the online learning platform & $S_{25}$ \\
\hline
\end{tabular}

\subsection{Weights of evaluation indicators based on AHP}

In order to reflect the importance of the online learning ability evaluation index for Japanese learners in different colleges, this paper uses the AHP method [17-21] to obtain the weights of the online learning ability evaluation index. Experts in the field were invited to evaluate and score the importance of evaluation index by using the same metrics, thereby obtaining the initial judgment matrix $\boldsymbol{A}$ for evaluation index:

$$
\mathbf{A}=\left[a_{i j}\right]_{n x n}
$$

where, $a_{i j}$ is the importance of the evaluation index $i$ relative to $j$, which is generally measured in the form of a 1-9 ratio, and satisfies $a_{i j}=1 / a_{j i} ; n$ is the number of evaluation indexes.

MATLAB was applied to obtain the maximum characteristic root $\lambda(\boldsymbol{A})$ of the initial judgment matrix. Then, the consistency index $C I$ can be calculated as:

$$
C I=(\lambda(\mathbf{A})-n) /(n-1)
$$

According to the number $n$ of evaluation indicators, the relevant tables were inquired to obtain the value of the consistency index. Then, the consistency ratio $C R$ is calculated as:

$$
C R=C I / R I
$$

If satisfying $C R<0.1$, it means that the initial judgment matrix $\boldsymbol{A}$ meets the consistency requirement, and the weight $w_{i}$ of the evaluation index $i$ for Japanese online learning ability among college students can be obtained as: 


$$
w_{i}=\sum_{j=1}^{n} a_{i j} / \sum_{i=1}^{n} \sum_{j=1}^{n} a_{i j}
$$

Thus, the weight sequence $\boldsymbol{W}$ of the evaluation index for all college students is given as:

$$
\mathbf{W}=\left[w_{1}, \cdots, w_{i}, \cdots, w_{n}\right]
$$

\subsection{Implementation of the evaluation model}

If the evaluation index $j$ of Japanese online learning ability among college students is a positive evaluation index, it's assumed that there are a total of $m$ evaluation objects, and the initial evaluation value of the $i$-th evaluation object about the evaluation index $j$ is $v_{i j}$. It was then standardized to derive the value $r_{i j}$ :

$$
r_{i j}=\left(v_{i j}-\min _{1 \leq i \leq m} v_{i j}\right) /\left(\max _{1 \leq i \leq m} v_{i j}-\min _{1 \leq i \leq m} v_{i j}\right)
$$

If the evaluation index of Japanese online learning ability of college students is a negative evaluation index, the standardized value is:

$$
r_{i j}=\left(\max _{1 \leq i \leq m} v_{i j}-v_{i j}\right) /\left(\max _{1 \leq i \leq m} v_{i j}-\min _{1 \leq i \leq m} v_{i j}\right)
$$

After the standardization process, it can be found hat all evaluation indicators are positive, and have uniform metrics. At this time, if the value $r_{i j}$ of the evaluation index $j$ increases, it means that it is closer to the optimal evaluation result; conversely, if $r_{i j}$ decreases, it is further away from the optimal evaluation result. Based on the above principles, a GRA model [22-25] for the evaluation of online learning ability of Japanese among college students was established, that is, the gray relational coefficient $\delta_{i j}$ between the evaluation index $j$ and the optimal result of the $i$-th evaluation object is given as:

$$
\delta_{i j}=\frac{\min _{i} \min _{j}\left|r_{i j}-\max _{1 \leq i \leq m} r_{i j}\right|+\beta \max _{i} \max _{j}\left|r_{i j}-\max _{1 \leq i \leq m} r_{i j}\right|}{\left|r_{i j}-\max _{1 \leq i \leq m} r_{i j}\right|+\beta \max _{i} \max _{j}\left|r_{i j}-\max _{1 \leq i \leq m} r_{i j}\right|}
$$

Furthermore, a gray relational coefficient matrix $\boldsymbol{\delta}$ for the evaluating the online learning ability of Japanese among college students was established, namely

$$
\boldsymbol{\delta}=\left[\delta_{i j}\right]_{m x n}
$$

Thus, we obtained the weighted gray relational degree $\kappa_{i}$ between the $i$-th evaluation object and the optimal result: 


$$
\mathbf{\kappa}=\boldsymbol{\delta} * \mathbf{W}^{T}=\left[\delta_{i j}\right]_{m \times n} *\left[w_{1}, \cdots, w_{i}, \cdots, w_{n}\right]^{T}=\left[\kappa_{i}\right]_{m \times 1}
$$

According to the comprehensive weighted gray relational degree $\kappa_{i}$, the authors obtained the pros and cons of the Japanese online learning ability among college students corresponding to different evaluation objects, namely

$$
\kappa_{o}=\max \left\{\left[\kappa_{i}\right]_{m x 1}\right\}=\kappa_{t}, \quad 1 \leq t \leq m
$$

Then the $t$-th evaluation object has the best online learning ability of Japanese language for college students.

\section{Conclusion}

The main conclusions of this study are reflected in the following aspects:

1. The problems existing in the online learning of Japanese among college students were discussed from different aspects such as technical support, platform professionalism and practicality, online learning resource planning, online learning resource sharing, online learning management and online learning evaluation etc., and the impacts of these factors on the cultivation of Japanese learning ability were also analyzed.

2. In order to improve the online learning ability among college students, the authors explored the implementation of the teaching model for Japanese among college students based on online learning from different perspectives: strengthening the construction of the Japanese online learning platform for college students, enriching the teaching resources of online learning, enhancing the ability to push professional knowledge of online learning, improving the interactive communication of Japanese online learning, and enhancing the evaluation of online learning of Japanese language among students.

3. The evaluation index system and GRA model for Japanese online learning ability of college students were established from multiple perspectives to realize the quantitative analysis of their online learning ability, which has good engineering application value.

\section{Acknowledgement}

Jilin Institute of Chemical Technology's Major Scientific Research Project "Research on the Cultivation of Japanese Learning Ability of College Students under JF Standard", Ji Hua Yuan Zhong Da He Zi [2019] No.026. 


\section{$7 \quad$ References}

[1] Rusli, R., Rahman, A., Abdullah, H. (2020). Student perception data on online learning using heutagogy approach in the Faculty of Mathematics and Natural Sciences of Universitas Negeri Makassar, Indonesia. Data in Brief, 29: 1-6. https://doi.org/10.1016/j.dib.2020.1051 $\underline{52}$

[2] Al Mamun, M. A., Lawrie, G., Wright, T. (2020). Instructional design of scaffolded online learning modules for self-directed and inquiry-based learning environments. Computers \& Education, 144: 1-17. https://doi.org/10.1016/j.compedu.2019.103695

[3] Wang, S. S. (2019). Development and Research of Online Education Theory. The Journal of Shandong Agricultural Engineering College, 36(2): 177-178. https://doi.org/ 10.15948/j.cnki.37-1500/x.2019.02.083

[4] Zhang, T. (2019). A study on the cultivation path of students' interest in learning in College Japanese Teaching under the framework of the new national standard. Western China Quality Education, (11): 154-155, 158. https://doi.org/ 10.16681/j.cnki.wcqe.201921091

[5] Fandiño, F. G. E., Muñoz, L. D., Velandia, A. J. S. (2019). Motivation and E-Learning English as a foreign language: A qualitative study. Heliyon, 5(9): 1-7. https://doi.org/10. 1016/j.heliyon.2019.e02394

[6] Lin, C. H., Zhang, Y. N., Zheng, B. B. (2017). The roles of learning strategies and motivation in online language learning: A structural equation modeling analysis. Computers \& Education, 113: 75-85. http://doi.org/10.1016/j.compedu.2017.05.014

[7] Wu, L., Zhang, P. (2020). Influence of Japanese-majored Undergraduates'Learning Attitudes on Learning Engagement and Educational Counter teaching Strategies in Big Data Age. Heilongjiang Researches on Higher Education, (1): 111-115.

[8] Li, L. (2020). The cultivation of students' interest in learning Japanese under the framework of the new national standard. PR Magazine, (2): 51. https://doi.org/10.16645/j.cnki. cnl 1-5281/c.2020.02.119

[9] Osipov, I. V., Prasikova, A. Y., Volinsky, A. A. (2015). Participant behavior and content of the online foreign languages learning and teaching platform. Computers in Human Behavior, (50): 476-488. http://doi.org/10.1016/j.chb.2015.04.028

[10] Buyse, K., Verlinde, S. (2013). Possible Effects of Free on Line Data Driven Lexicographic Instruments on Foreign Language Learning: The Case of Linguee and the Interactive Language Toolbox. Procedia - Social and Behavioral Sciences, 95: 507-512. http://doi.org/ 10.1016/j.sbspro.2013.10.675

[11] Jiang, P. (2019). A Comparative Study of Online Learning Platforms for Online Courses between Chinese and American Universities from the Perspective of Knowledge Transformation. Journal of Hebci University of Science and Technology (Social Sciences), 19(3): 83-90. http://dx.doi.org/10.3969/j.issn.1671-1653.2019.03.0138

[12] Gao, L., Qin, G.H. (2017). Research on the construction of digital environment of Japanese teaching from the perspective of ecology. The Journal of Shandong Agricultural Engineering College, 34(8): 64-65. https://doi.org/10.15948/j.cnki.37-1500/s.2017.08.032

[13] Zhou, M. (2018). A study on the teaching reform of Japanese as a second foreign language -Based on the investigation and analysis of the current situation of students' study in the Foreign Language College of Guangzhou Maritime University. Western China Quality Education, (22): 149-150. https://doi.org/10.16681/j.cnki.wcqe.201822085

[14] Rajesh, R. (2020). A grey-layered ANP based decision support model for analyzing strategies of resilience in electronic supply chains. Engineering Applications of Artificial Intelligence, 87: 1-18. https://doi.org/10.1016/j.engappai.2019.103338 
[15] Memon, M. S., Lee, Y. H., Mari, S. I. (2015). Group multi-criteria supplier selection using combined grey systems theory and uncertainty theory. Expert Systems with Applications, 42(21): 7951-7959. http://doi.org/10.1016/j.eswa.2015.06.018

[16] Kumar, K. (2018). A Spectrum Handoff Scheme for Optimal Network Selection in NEMO based Cognitive Radio Vehicular Networks: A Cost Function MADM Method based on Grey Theory based Approach. Procedia Computer Science, 125: 275-281. https://doi.org/ 10.1016/j.procs.2017.12.037

[17] Ardjmand, M., Daneshfar, M. A. (2020). Selecting a suitable model for collecting, transferring, and recycling drilling wastes produced in the operational areas of the Iranian offshore oil company (IOOC) using analytical hierarchy process (AHP). Journal of Environmental Management, 259: 1-12. https://doi.org/10.1016/j.jenvman.2019.109791

[18] Suganthi, L. (2018). Multi expert and multi criteria evaluation of sectoral investments for sustainable development: An integrated fuzzy AHP, VIKOR / DEA methodology. Sustainable Cities and Society, 43: 144-156. https://doi.org/10.1016/j.scs.2018.08.022

[19] Ramya, S., Devadas, V. (2019). Integration of GIS, AHP and TOPSIS in evaluating suitable locations for industrial development: A case of Tehri Garhwal district, Uttarakhand, India. Journal of Cleaner Production, 238: 1-14. https://doi.org/10.1016/j.jclepro.2019.117 $\underline{872}$

[20] Baffoe, G. (2019). Exploring the utility of Analytic Hierarchy Process (AHP) in ranking livelihood activities for effective and sustainable rural development interventions in developing countries. Evaluation and Program Planning, 72: 197-204. https://doi.org/10.1016/j. evalprogplan.2018.10.017

[21] Seyedmohammadi, J., Sarmadian, F. (2019). Ali Asghar Jafarzadeh, et al. Development of a model using matter element, AHP and GIS techniques to assess the suitability of land for agriculture. Geoderma, 352: 80-95. https://doi.org/10.1016/j.geoderma.2019.05.046

[22] Lee, C., Lee, J. W., Ryu, S. G., Oh, J. H. (2019). Optimum design of a large area, flexure based $\mathrm{XY} \theta$ mask alignment stage for a 12-inch wafer using grey relation analysis. Robotics and Computer-Integrated Manufacturing, 58: 109-119. https://doi.org/10.1016/j.rcim.20 $\underline{19.02 .005}$

[23] Kumar, J., Soota, T. (2020). Multi-response optimization of machining parameter for Zircaloy by response surface methodology and grey relation analysis. Materials Today: Proceedings, 125: 1544-1550. https://doi.org/10.1016/j.matpr.2019.11.084

[24] Heidari, S., Naseri, M., Gheibi, R., Baghfalaki, M., Pourarian, M. R., Farouk, A. (2017). A new quantum watermarking based on quantum wavelet transforms. Communications in theoretical Physics, 67: 732-742. https://doi.org/10.1088/0253-6102/67/6/732

[25] Yazdani, M., Kahraman, C., Zarate, P., Onar, S. C. (2019). A fuzzy multi attribute decision framework with integration of QFD and grey relational analysis. Expert Systems with Applications, 115: 474-485. https://doi.org/10.1016/j.eswa.2018.08.017

\section{Authors}

Dongmei Jin a lecturer at Jilin Institute of Chemical Technology, graduated from Northeast Normal University. She has been engaged in Japanese teaching and scientific research for many years. She has successively taught many basic courses and backbone courses of Japanese major, such as basic Japanese, advanced Japanese, extensive Japanese reading Japanese listening and so on. She has rich experience in teaching and scientific research. Presided over the research of one major social sci- 
ence project at school level, presided over and participated in a number of scientific research projects at school level, participated in the research of one scientific research project of the Provincial Federation of Social Sciences, and participated in the completion of one educational reform project of the Provincial Department of education. She has published more than 10 academic papers in provincial journals, one of which is a core Chinese journal and one is searched by CPCI. With strong scientific research ability and rich teaching experience.

Yiping Li works for College of Foreign Languages, Jilin Institute of Chemical Technology, Jilin 132022, China.

Article submitted 2020-06-01. Resubmitted 2020-07-05. Final acceptance 2020-07-08. Final version published as submitted by the authors. 